\title{
Cable Fire Spread in Electronic Cabinet
}

\author{
Lili Kong, Li Tian and Haishun Xu \\ Institute of Safety Engineering, China Jiliang University, Hangzhou, Zhejiang 310018, China
}

\begin{abstract}
According to the characteristics of the electronic cabinet fire, several cases of cable fire experiments with different ventilation rate in real scale electronic cabinet have been carried out. Temperatures of the cable flame and fume, as well as different location near the center of the conflagrant electronic cabinet were measured as a function of time. The results show significant effects of the ventilation rate on the temperature near the center of the cabinet and the concentration variation of $\mathrm{CO}$ and $\mathrm{O}_{2}$, but the influence on the spread of cable fire is not obvious. The results provide useful reference for early warning and rapidly extinguishing fire of the electronic cabinet at the early stage.
\end{abstract}

\section{Keywords-electronic cabinet; cable fire; ventilation rate}

\section{INTRODUCTION}

Electronic cabinet such as program-controlled switching equipment is widely used in business and service industry. This electronic cabinet is always arranged in arrays in control room and filled with printed circuit boards (PCB). Although the flame retardant grade of the PCB used in cabinet has reached the level of UL94V-0 (Test for Flammability of Plastic Materials for Parts in Devices and Appliances) [1-2], the cable fire accident in cabinet always occurs due to various reasons. The hot flue gas produced by cable flame will lead the PCB and components to pyrolysis and generates large amounts of deleterious and corrosive gases, which spread into control room through the ventilation grille at the top of the control cabinet; then corrode and disable the electronic equipment. Meanwhile, the flame will also spread out of the electronic cabinet under certain condition, ignite adjacent electronic cabinet and finally evolve into overall fire. Compared with civil building and public place, control room is always unattended operation so that it may has less casualties. But the economic costs results from cabinet fire are extremely heavy not only on direct losses of burned-out equipment but on indirect losses caused by production disruption. Researches on the origin and the development of cable fire in communication system, petrochemical industry and nuclear plant area have been done (Norman Alvares, 2000; J. L. Lee,1981;Schultz, Neil,1986;O. Keshki-Rahkonen, 2002) [3-6]. Besides, J. Mangs has finished the experimental research about the full scale emulation of electronic cabinet fire [7]. This research contributes quantitative study and data of the electronic cabinet fire, which can provide foundation for early warning and rapidly extinguishing fire at the early stage.

\section{EXPERIMENTS}

\section{A. Experimental Apparatus}

The experimental apparatus for this study is shown in
Figure 1. The electronic cabinet is standard with a 1650 millimeters $\times 450$ millimeters $\times 480$ millimeters size and a rectangle fireproof observation window is provided in the front of the cabinet for the camera to record the flame propagation process. At the top and side of the cabinet, there are three ventilation grilles with a 0.004 square meters ventilation area of each grille. Various ventilation volume can be achieved via controlling the valve of the blower at the bottom of the cabinet for simulating the flame propagation process and the variation of the parameters in the cabinet. Two sets of type K (chromelalumel) sheathed thermocouples arrays are respectively installed in the cabinet. Thermocouples 1-5 are close to the cables with a 20 centimeters spacing from each other to measure the temperature of the cable fire. The temperature variation in the fire spread cabinet is measured by thermocouples 6-9, located at the geometrical center of the cabinet with a 25 centimeters adjacent gap. A Vario Plus flue gas analyzer (made by MRU Company) located underneath the top of the cabinet for 10 centimeters is used to analyze the fire fume.

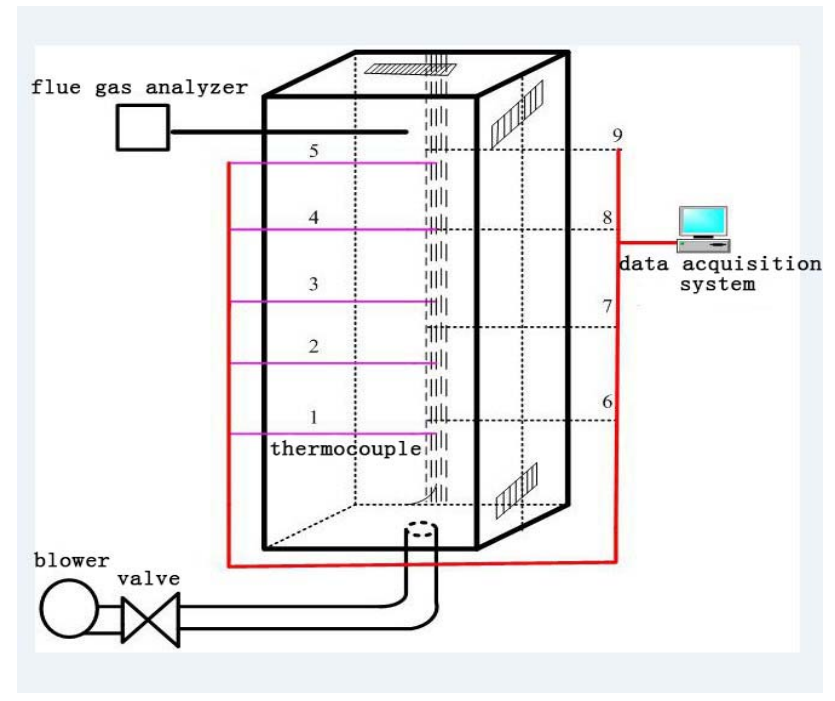

FIGURE I. SCHEME OF THE EXPERIMENTAL SYSTEM

\section{B. Experimental Method}

Before the experiment, arrange five cables vertically at the back of the cabinet. Ignition starts with a burning square basin of 15 cubic centimeters gasoline, located at the bottom of the cabinet with a 5 centimeters $\times 5$ centimeters cross area and can totally generate 20 kilojoules ignition energy [7]. The flame of the gasoline ignites and spreads along the cables until it is out. The actual mass of the cables burnt in each experiment is in the order of 2.31 kilograms while the combustible mediums in the 
cables is 1.87 kilograms (Table 1). Combined with actual situation, natural ventilation and two kinds of forced ventilation are simulated in the experimental cabinet (Table 2).

\section{TABLE I. PROPERTY AND CONTENTS OF THE CABLES}

\begin{tabular}{|l|l|}
\hline \multicolumn{1}{|c|}{ Property } & \multicolumn{1}{c|}{ Contents } \\
\hline Cable type & $\begin{array}{l}\text { Non flame-retardant rubber jacketed } \\
\text { copper quadded cable YZ450/700 }\end{array}$ \\
\hline $\begin{array}{l}\text { Outside diameter/mass of } \\
\text { unit length }\end{array}$ & $14 \mathrm{~mm} / 0.28 \mathrm{~kg}$ \\
\hline $\begin{array}{l}\text { Insulator thickness of each } \\
\text { wire in cable }\end{array}$ & $1 \mathrm{~mm}$ (accounts for 26\% of the total mass) \\
\hline Thickness of over sheath & $3 \mathrm{~mm}$ (accounts for $53 \%$ of the total mass) \\
\hline Textile fiber & $2 \%$ (accounts for $2 \%$ of the total mass) \\
\hline Copper conductor & $19 \%$ (accounts for $19 \%$ of the total mass) \\
\hline Combustible medium & $81 \%$ (accounts for $81 \%$ of the total mass) \\
\hline $\begin{array}{l}\text { Number of cable in each } \\
\text { experiment }\end{array}$ & five (length of each cable is $1.65 \mathrm{~m}$ ) \\
\hline
\end{tabular}

TABLE II. EXPERIMENTAL CONDITIONS

\begin{tabular}{|l|l|}
\hline Condition1 & Natural ventilation \\
\hline Condition2 & $\begin{array}{l}\text { Forced ventilation (air quantity } 0.00283 \mathrm{~m} 3 / \mathrm{s} \text {, ventilate the } \\
\text { cabinet every two minutes) }\end{array}$ \\
\hline Condition3 & $\begin{array}{l}\text { Forced ventilation (air quantity } 0.00567 \mathrm{~m} 3 / \mathrm{s} \text {, ventilate the } \\
\text { cabinet per minute) }\end{array}$ \\
\hline
\end{tabular}

\section{RESULTS AND DisCUSSION}

\section{A. Influence of Various Ventilation Rates on Flame Spread Velocity}

Temperature of the cable fire with different ventilation rates as a function of the time is presented in Figure 2.Typical height of the flame without ventilation is shown in Figure 3. Combined with the height of the flame recorded by camera, the average spread velocity of the flame can be calculated using the time interval and the average distance of the two peak signals which come from the flame front passing through the adjacent two measuring points. Table 3 shows the average spread velocity of the flame under different ventilation conditions.

Applying ventilation rate in electronic cabinet is mainly for the heat dissipation of the electronic equipment, which has a lower airflow velocity for unit section. For instance, the average airflow velocity for unit section is only $0.02 \mathrm{~m} / \mathrm{s}$ when the ventilation rate is $0.00567 \mathrm{~m} 3 / \mathrm{s}$ (ventilate the cabinet per minute). As a consequence, various ventilation rates have slightly influence on the flame spread velocity.

TABLE III. FIAME SPREAD VELOCITY AT DIFFERENT VENTILATION CONDITIONS

\begin{tabular}{|c|c|}
\hline Condition & Velocity $(\mathbf{c m} / \mathbf{s})$ \\
\hline Natural ventilation & 0.51 \\
\hline Ventilation rate $0.00283 \mathrm{~m} 3 / \mathrm{s}$ & 0.60 \\
\hline Ventilation rate $0.00567 \mathrm{~m} 3 / \mathrm{s}$ & 0.68 \\
\hline
\end{tabular}

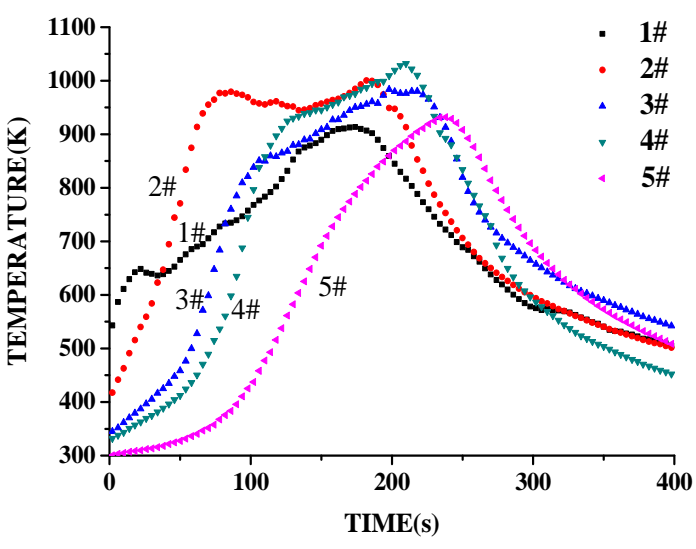

(a) Natural Ventilation

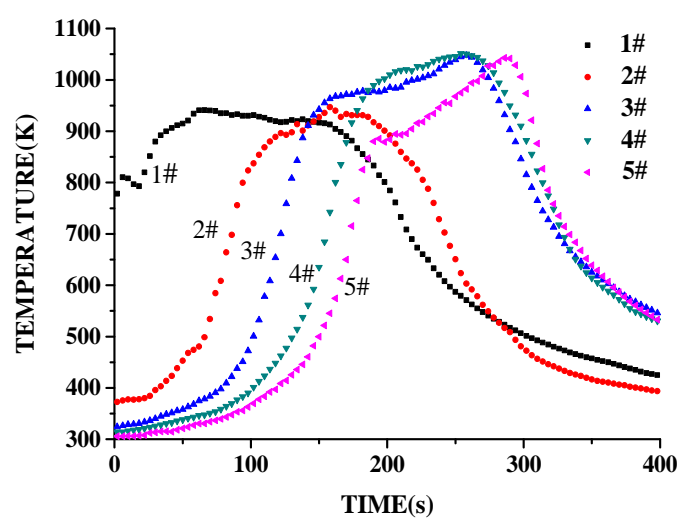

(b) Ventilation Rate $0.00283 \mathrm{~m} 3 / \mathrm{s}$

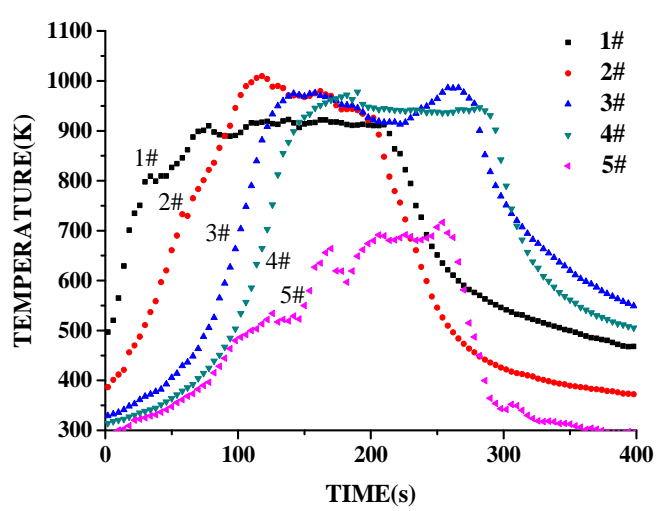

(c) Ventilation Rate $0.00567 \mathrm{~m} 3 / \mathrm{s}$

FIGURE II. FLAME TEMPERATURE CURVES AT DIFFERENT VENTILATION RATES 


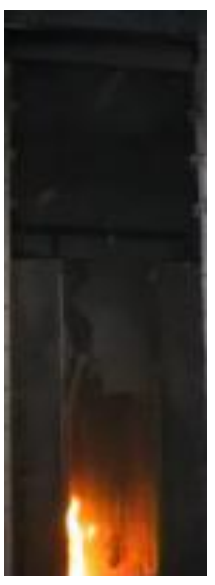

30 s

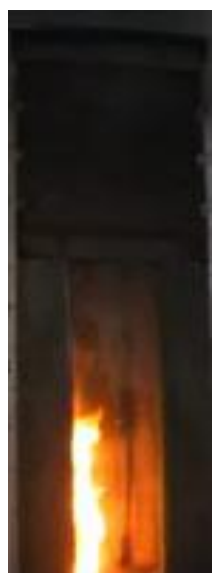

120 s

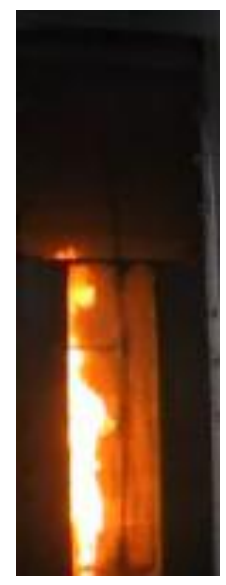

180 s

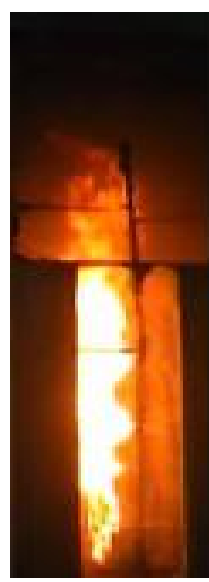

270s

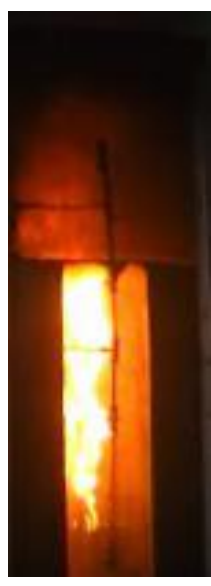

300 s
FIGURE III. FLAME HEIGHT AT WITHOUT FORCED VENTILATION CONDITION

B. Variation Rule of the Ttemperature at the Central of the Cabinet with Different Ventilation Rates

For the three ventilation rates, the temperature variation at different positions has various tendencies which is different from the flame spread velocity (Figure 4).When use natural ventilation, the temperature is less than 373 Kelvin measured by thermocouple $6 \#$, 7\#, and $8 \#$, which may not cause deadly thermal disaster to the PCB in electronic cabinet. With the increase of ventilation rate, the temperature increases significantly and the PCB start to pyrolyse. But the highest temperature measured by thermocouple $9 \#$ is always more than 673 Kelvin in the three cases and the PCB near the place will dramatically pyrolyse, resulting the control equipment brokendown. During the experiments, the flame for each ventilation rate always rushes out of the cabinet through the ventilation grille when it reaches to the top of the cabinet, easily ignite the cables in the cable bridge on the top of the cabinet and the adjacent cabinets which may finally evolve to the overall fire.

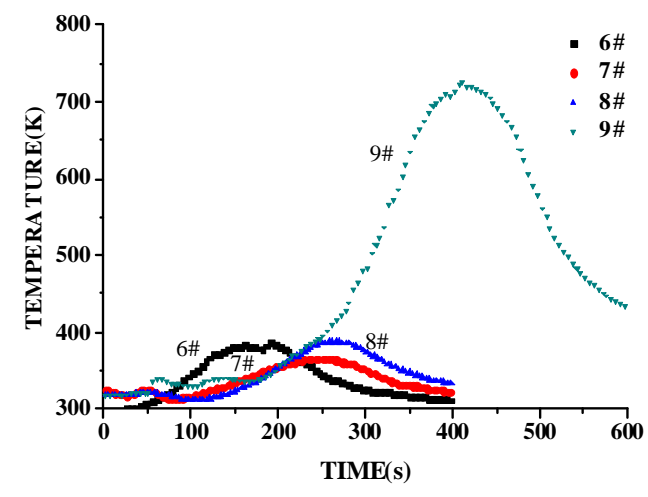

(a) Natural Ventilation

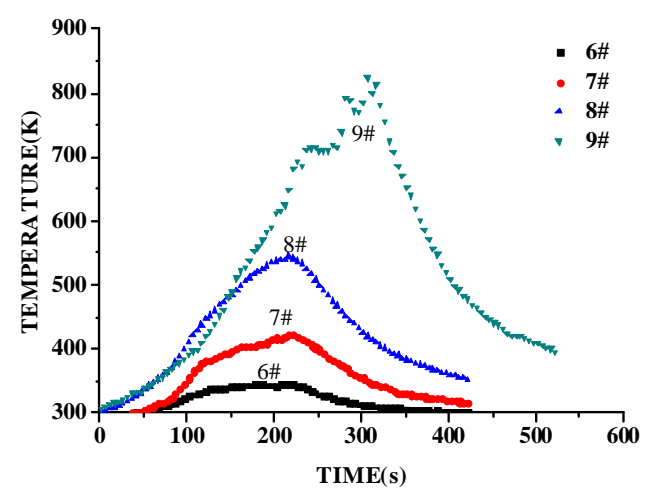

(b) Ventilation Rate $0.00283 \mathrm{~m} 3 / \mathrm{s}$

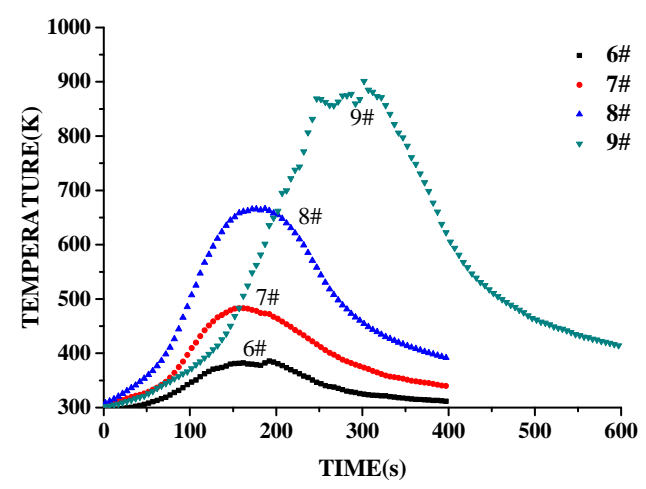

(c) Ventilation Rate $0.00567 \mathrm{~m} 3 / \mathrm{s}$

FIGURE IV. TEMPERATURE CURVES IN DIFFERENT LOCATION AT THE CENTER OF THE CDABINHET

\section{Concentration Variation Rule of $\mathrm{CO}$ and $\mathrm{O}_{2}$ at the Top of the Cabinet}

With different ventilation rates, the generation rate of the $\mathrm{CO}$ and the consumption rate of the $\mathrm{O}_{2}$ at the top of the cabinet are proportional to the ventilation rate (Figure 5). A similar phenomenon for each ventilation rate is that the cable fire in the cabinet has already burnt out before the generation rate of the $\mathrm{CO}$ and the consumption rate of the $\mathrm{O}_{2}$ reach to the maximum (combine Figure 2 and Figure 5). This situation can be 
explained in two main respects. On one hand, forced ventilation makes the velocity of the ascending fume become faster. On the other hand, cable fire is a typical solid fire which may have the possibility of smoldering though the fire has burnt out. The fume spread out through the ventilation grille and the fresh $\mathrm{O}_{2}$ simultaneously supplies into the cabinet which leads the concentration of $\mathrm{CO}$ to lower and $\mathrm{O}_{2}$ to higher until to normal range.
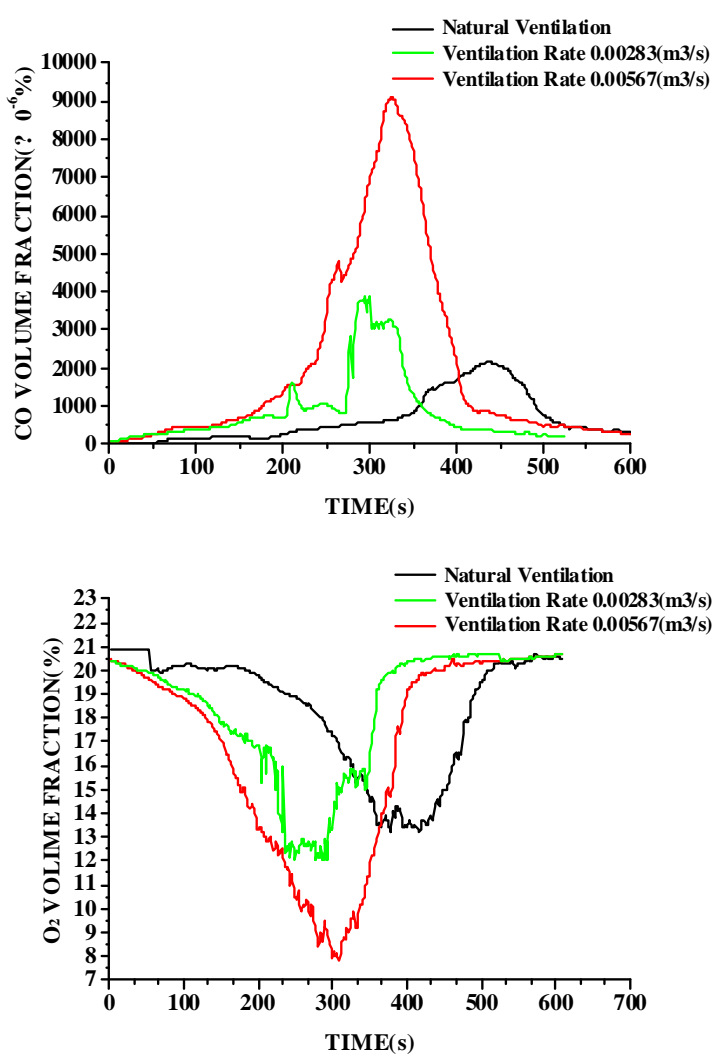

FIGURE V. CONCENTRATION VARIATION OF CO AND O $\mathrm{O}_{2}$ AT DIFFERENT VENTILATION CONDITION

\section{CONCLUSION}

1) Cable fire of electronic cabinet spread relatively slowly, but the heat fume generated by the fire will make the PCB pyrolyse in the cabinet which may cause heavy direct and indirect economic loss.

2) Common ventilation rate has slightly influence on the spread velocity of the cable fire which is contrary to the temperature field of the electronic cabinet. When the ventilation rate is increased, the temperature of the central of the cabinet increases quickly, which may do harm to the electronic equipment. Furthermore, a mass of toxic fume will be produced and the local fire may transform into the overall fire.

\section{ACKNOWLEDGMENT}

The authors acknowledge the support provided by the International Science \& Technology Cooperation Program of China (2013DFG71760).

\section{REFERENCE}

[1] Mu Li, and Qiang yao, “Application of pyrolysis in recycle and disposal of waste printed circuit board," Techniques and Equipment for Environmental Pollution Control, vol. 7, 2006, pp. 107-110.

[2] Takashi Yamawaki, "The gasification recycling technology of plastics WEEE containing brominated flame retardants,” Fire and Materials, vol. 27, 2003, pp. 315-319.

[3] Norman A, Lvares A, and Fernandez-Pello, "Fire initiation and spread in overloaded communication system cable trays,” Experimental Thermal and Fluid Science, vol. 21, 2000, pp.51-57.

[4] J L Lee, "A study of damageability of electrical cables in simulated fire environments,” Electric Power Research Institute, 1981, PP.3-27, California.

[5] Schultz, Neil, "Fire protection for cable trays in petrochemical facilities,” Plant/Operation Progress, vol. 5, 1986, pp. 35-39.

[6] O. Keshki-Rahkonen, and J. Mangs, "Electrical ignition sources in nuclear power plants: statistical, modeling, and experimental studies," Nuclear Engineering and Design, vol. 213, 2002 pp. 209-221.

[7] VYTENIS Babrauskas, "The SFPE handbook of fire protection engineering,” 2nd Edition. Boston: Society of Fire Protection Engineers, National Fire Protection Association, 1995, PP.1-4. 